\title{
Neuro-Second Order Sliding Mode Field Oriented Control for DFIG Based Wind Turbine
}

\author{
Habib BENBOUHENNI* \\ *National Polytechnique School of Oran Maurice Audin, Oran, Algeria \\ (habib0264@gmail.com) \\ $\$$ Corresponding Author; Habib Benbouhenni, BP: 50B Ouled Fares Chlef, Algeria, Tel: +213663956329, \\ habib0264@gmail.com
}

Received: 25.11.2018 Accepted:18.12.2018

\begin{abstract}
In this paper, we present a comparative study between second order sliding mode control (SOSMC) with two-level pulse width modulation (2L-PWM) and neuro-second order sliding mode control (NSOSMC) with two-level fuzzy space vector modulation (2L-FSVM) of reactive stator power and active stator power control of the doubly fed induction generator (DFIG) for wind energy conversion systems (WECSs). The validity of the proposed controls techniques is verified by simulation tests of the DFIG-based wind turbine systems (WTSs). The total harmonic distortion (THD) of rotor current, reactive stator power, electromagnetic torque and active stator power is determined and compared in the above strategies. The obtained results showed that the proposed NSOSMC control with 2L-NSVM technique have electromagnetic torque, reactive stator power and active power with low ripples and low rotor current harmonic distortion than SOSMC control scheme with conventional PWM technique..
\end{abstract}

Keywords Doubly fed induction generator, second order sliding mode control, neuro-second order sliding mode, wind energy conversion system, fuzzy space vector modulation, pulse width modulation, total harmonic distortion, wind turbine system.

\section{Nomenclature}

DFIG

SOSMC

NSOSMC

PWM

SVM

FSVM

FL

ANN

THD

$P_{s}$

$Q_{s}$

$V_{s}, V_{r}$

$I_{s}, I_{r}$

$\psi_{s}, \psi_{r}$

$R_{s}, R_{r}$

$L_{s}, \mathrm{~L}_{\mathrm{r}}$

$L_{m}$

$\Omega$

$J$

F

$P$
Doubly fed induction generator.

Second order sliding mode control.

Neuro-second order sliding mode control.

Pulse width modulation.

Space vector modulation.

Fuzzy space vector modulation.

Fuzzy logic.

Artificial neural network.

Total harmonic distortion.

Active power.

Reactive power.

Stator and rotor voltages.

Stator and rotor currents.

Stator and rotor fluxes

Stator and rotor resistances

Stator and rotor self-inductances

Mutual inductance.

Angular speed of the turbine.

Inertia.

Viscous friction coefficient.

Number of pole pairs.

\section{Introduction}

Sliding mode control (SMC) is becoming one of the most important control techniques of systems. This strategy was proposed by Utkin in 1977 . Hence, SMC is a variable structure control technique. However, the robustness is the best advantage of the sliding mode control technique. On the other hand, the major disadvantage of the SMC technique is that the chattering phenomenon caused by the discontinuous control action [1]. In order to improve the SMC performances a complimentary use of the artificial neural network (ANN), SOSMC controller and fuzzy logic (FL) controller is proposed. In [2], an SOSMC method was designed to control the reactive and active powers of a dualrotor wind turbine system. FL controller and SMC are combined to control DFIG [3]. In [4], a modified direct torque control (DTC) technique was proposed based on SOSMC control to regulate the rotor flux and electromagnetic torque. SOSMC and artificial neural networks (ANNs) are combined to control doubly fed induction generators [5]. A discrete sliding mode controller 
is designed to control the real and active power of doubly fed induction generator [6]. In [7], direct power control (DPC) technique based on SOSMC controller has been proposed.

Since FL technique has generated a good deal of interest in certain applications. The advantages of fuzzy logic over the traditional controllers are: it does not need an accurate mathematical model, it is a simple control, it can work with imprecise inputs, it can handle non-linearity, it is easy to implement, and it is more robust than traditional nonlinear controllers [8]. This strategy is simple control and easy to implement compared to traditional controls. However, FL has been applied to many fields, from control theory to artificial intelligence. The FL control theory was proposed by Zadeh in 1965.

In this work, two control schemes will be compared with each other. These two control strategies are conventional SOSMC control with PWM technique and NSOSMC control with NSOSMC-FSVM. The proposed control scheme is verified by both the simulation results. Simulation results show the clearly depicts reduction of electromagnetic torque, THD value of rotor current and powers ripples in proposed NSOSMC-FSVM control scheme.

\section{The DFIG model}

The traditional electrical equations of the doubly fed induction generator in the Park transformation are written as follows $[9,10]$ :

$$
\begin{aligned}
& \left\{\begin{array}{l}
\mathrm{v}_{\mathrm{ds}}=\mathrm{R}_{\mathrm{s}} \mathrm{I}_{\mathrm{ds}}+\frac{\mathrm{d}}{\mathrm{dt}} \psi_{\mathrm{ds}}-\omega_{\mathrm{s}} \psi_{\mathrm{qs}} \\
\mathrm{v}_{\mathrm{qs}}=\mathrm{R}_{\mathrm{s}} \mathrm{I}_{\mathrm{qs}}+\frac{\mathrm{d}}{\mathrm{dt}} \psi_{\mathrm{qs}}+\omega_{\mathrm{s}} \psi_{\mathrm{ds}} \\
\mathrm{V}_{\mathrm{dr}}=\mathrm{R}_{\mathrm{r}} \mathrm{I}_{\mathrm{dr}}+\frac{\mathrm{d}}{\mathrm{dt}} \psi_{\mathrm{dr}}-\omega_{\mathrm{r}} \psi_{\mathrm{qr}} \\
\mathrm{v}_{\mathrm{qr}}=\mathrm{R}_{\mathrm{r}} \mathrm{I}_{\mathrm{qr}}+\frac{\mathrm{d}}{\mathrm{dt}} \psi_{\mathrm{qr}}+\omega_{\mathrm{r}} \psi_{\mathrm{dr}}
\end{array}\right. \\
& \left\{\begin{array}{l}
\psi_{d s}=L_{s} I_{d s}+M I_{d r} \\
\psi_{q s}=L_{s} I_{q s}+M I_{q r} \\
\psi_{d r}=L_{r} I_{d r}+M I_{d s} \\
\psi_{q r}=L_{r} I_{q r}+M I_{q s}
\end{array}\right.
\end{aligned}
$$

The power equations are defined as:

$$
\left\{\begin{array}{l}
P_{S}=\frac{3}{2}\left(V_{d s} I_{d s}+V_{q s} I_{q S}\right) \\
Q_{S}=\frac{3}{2}\left(V_{q s} I_{d s}-V_{d s} I_{q s}\right)
\end{array}\right.
$$

The mechanical equation :

$$
T_{e}=T_{r}+J \cdot \frac{d \Omega}{d t}+f \cdot \Omega
$$

\section{Two-level FSVM technique}

In modulation strategies, SVM is a technique for the control of the PWM inverter. It is used for the creation of alternating current waveforms. This modulation reduced the total harmonic distortion (THD) of stator voltages compared to the PWM technique. On the other hand, this modulation technique is detailed in [11-14]. This strategy needs to calculated the angle and sector. This strategy is difficult to implement. In [15], the author proposes a new algorithm of the three-level SVM inverter based on calculating the maximum (max) and minimum ( $\min$ ) of the three-phase voltages. This proposed technique is a simple modulation scheme and easy to implement compared to the traditional SVM strategy.

In this part, we proposed a new SVM algorithm of the two-level inverter based on the calculation of max and min of three-phase voltages $(\mathrm{Va}, \mathrm{Vb}, \mathrm{Vc})$. On the other hand, this proposed modulation scheme is not needed to calculate the angle and sector, easy to implement and simple modulation scheme. The proposed SVM algorithm which is designed to control the two-level inverter is shown in Fig. 1(See Appendix).

In addition, this modulation technique has the following drawbacks. This technique gives more power ripples, rotor flux, electromagnetic torque and total harmonic distortion of rotor current. To overcome these drawbacks lead to the development of a sophisticated space vector modulation strategy this is fuzzy space vector modulation (FSVM). This strategy is proposed by $\mathrm{H}$. Benbouhenni et al. $[15,16]$. However, this strategy gives more and more the total harmonic distortion of rotor current compared to traditional SVM and PWM technique. Furthermore, it minimizes the stator reactive and active powers ripple of the doubly fed induction generator-based WTSs. On the other hand, the two-level FSVM modulation scheme is not needed to calculate the sector and angle, a simple modulation scheme and easy to implement.

The principle of the two-level FSVM is similar to conventional SVM technique. However, the hysteresis comparators are replaced by FL controllers and this strategy based on the FL classification has the advantage of simplicity and easy implementation. The structure of two-level SVM based on FL controllers is shown in Fig. 2 (See Appendix).

Since the FL controller has been used in several application. However, this strategy was introduced by Zadeh [17]. In the FL method, does not need a mathematical model [18]. The block diagram of FL controllers based hysteresis comparators is shown in Fig. 3 (See Appendix). Table 1 and Table 2 shows the parameters and rules of the FL controller respectfully.

Table 1. Parameters of FL controller

\begin{tabular}{|l|l|}
\hline Fis type & Mamdani \\
\hline And method & Min \\
\hline Or method & Max \\
\hline Implication & Min \\
\hline Aggregation & Max \\
\hline Defuzzification & Centroid \\
\hline
\end{tabular}


Table 2. The Rules Matrix of the controllers

\begin{tabular}{|c|l|l|l|l|l|l|l|}
\hline $\mathbf{e}$ & NB & NM & NS & EZ & PS & PM & PB \\
\cline { 1 - 6 } ye & & & & & & & \\
\hline NB & NB & NB & NB & NB & NM & NS & EZ \\
\hline NM & NB & NB & NB & NM & NS & EZ & PS \\
\hline NS & NB & NB & NM & NS & EZ & PS & PM \\
\hline EZ & NB & NM & NS & EZ & PS & PM & PB \\
\hline PS & NM & NS & EZ & PS & PM & PB & PB \\
\hline PM & NS & EZ & PS & PM & PB & PB & PB \\
\hline PB & EZ & PS & PM & PB & PB & PB & PB \\
\hline
\end{tabular}

With :

NB: Negative Big.

NM: Negative Middle.

NS: Negative Small.

PS: Positive Small.

PB: Positive Big.

EZ: Equal Zero.

PM: Positive Middle.

The membership function definition for the input variables and output membership is given by Fig. 4 .
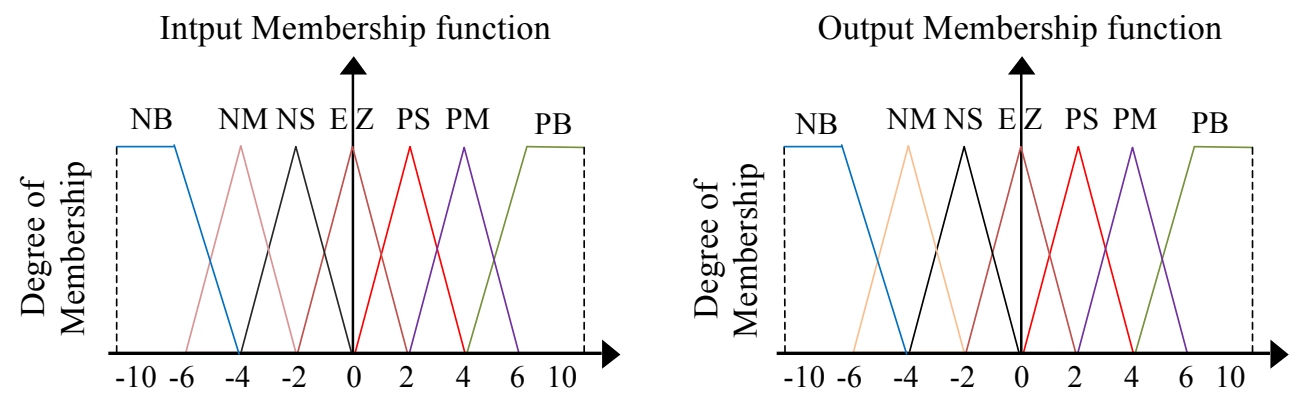

Fig. 4. Fuzzy sets and its memberships functions.

\section{NSOSMC control}

In control systems, the sliding mode controller does not need accurate mathematical models like traditional controllers. The theory of this technique has been studied and developed in the Soviet Union, first by Professor Emelyanov [19]. Then by other collaborators like Utkin, from the study's results of the mathematician Filippov on the discontinuous second-member differential equations. Then the works were resumed in the United States by Slotine in Japan by Young, Harashima and Hashimoto.

The SMC control has an essential disadvantage, which is the chattering phenomenon. On the other hand, this strategy gives more powers ripples and total harmonic distortion of stator voltages. In order to improve the SMC performances, a complimentary use of the second order sliding mode controller (SOSMC) and artificial neural networks (ANNs) is proposed. The SOSMC is a particular operation mode of variable structure systems. However, the SOSMC control has attracted much research on control systems. The neurosecond order sliding mode controller (NSOSMC) is simple control scheme, easy to implement and reduced more and more the electromagnetic torque ripple, stator flux ripple and powers ripples of a DFIG compared to the SMC control. The SOSMC control with PWM technique, which is designed to control stator reactive and active powers of the doubly fed induction generator, is shown in Fig. 5.

The second order sliding mode reactive and active controllers are designed to respectively change the $d$ and $q$ axis voltages $\left(\mathrm{V}_{\mathrm{rd}}\right.$ and $\left.\mathrm{V}_{\mathrm{rq}}\right)$ as in equations (5) and (6).

$V_{d r}=u_{1}+u_{2}$

$V q r=w 1+w 2$
With:

$$
\begin{aligned}
& {\left[\begin{array}{l}
u 1 \\
u 2
\end{array}\right]=\left[\begin{array}{c}
-\lambda_{1} \operatorname{sign}\left(S_{q}\right) \\
-\delta 1\left|S_{q}\right|^{0.5} \operatorname{sign}\left(S_{q}\right)
\end{array}\right]} \\
& {\left[\begin{array}{l}
w 1 \\
w 2
\end{array}\right]=\left[\begin{array}{c}
-\lambda_{2} \operatorname{sign}\left(S_{p}\right) \\
-\delta_{2}\left|S_{p}\right|^{0.5} \operatorname{sign}\left(S_{p}\right)
\end{array}\right]}
\end{aligned}
$$

To ensure the convergence of controllers in the infinity of time constants and are chosen to satisfy the following inequality:

$$
\left\{\begin{array}{c}
\lambda_{i} \leq \frac{\mu_{i}}{\sigma \cdot L_{r}} \\
\delta_{i} \geq \frac{4 \mu_{i}\left(\lambda_{i}+\mu_{i}\right)}{\left(\lambda_{i}-\mu_{i}\right)\left(L_{r} \sigma\right)^{2}} \\
\left|A_{i}\right| \prec \mu_{i} ; i=1,2
\end{array}\right.
$$

The application of the ANNs attracts the attention of many scientists from all over the world [20]. This strategy has many advantages, it is a simple control, easy to implement, the possibility of approximating non-linear function, insensitivity to the distortion of the network [21]. The neuro-second order sliding mode controller (NSOSMC) is similar to a conventional SOSMC control. However, the switching controllers term $\operatorname{sign}(\mathrm{S}(\mathrm{x}))$, has been replaced by ANN controllers as given by Fig. 6 (See Appendix). However, the NSOSMC control reduced more and more powers ripples, electromagnetic torque ripple, rotor flux 
ripple and total harmonic distortion of stator voltages compared to classical SOSMC technique.

The structure of the ANN controller to perform the SOSMC applied DFIG satisfactorily was a NNs with 1 linear input node, 8 neurons in the hidden layer, and 1 neuron in the output layer. As shown in Fig. 7 (See Appendix). The ANN controller is composed of two layers, Layer 1 (Fig.8) and Layer 2 (Fig. 9) respectly (See Appendix).
The Fig. 10 (See Appendix) show the block diagram of the internal structure of hidden layer. The convergence of the network in summer obtained by using the value of the parameters grouped in the Table 3 .

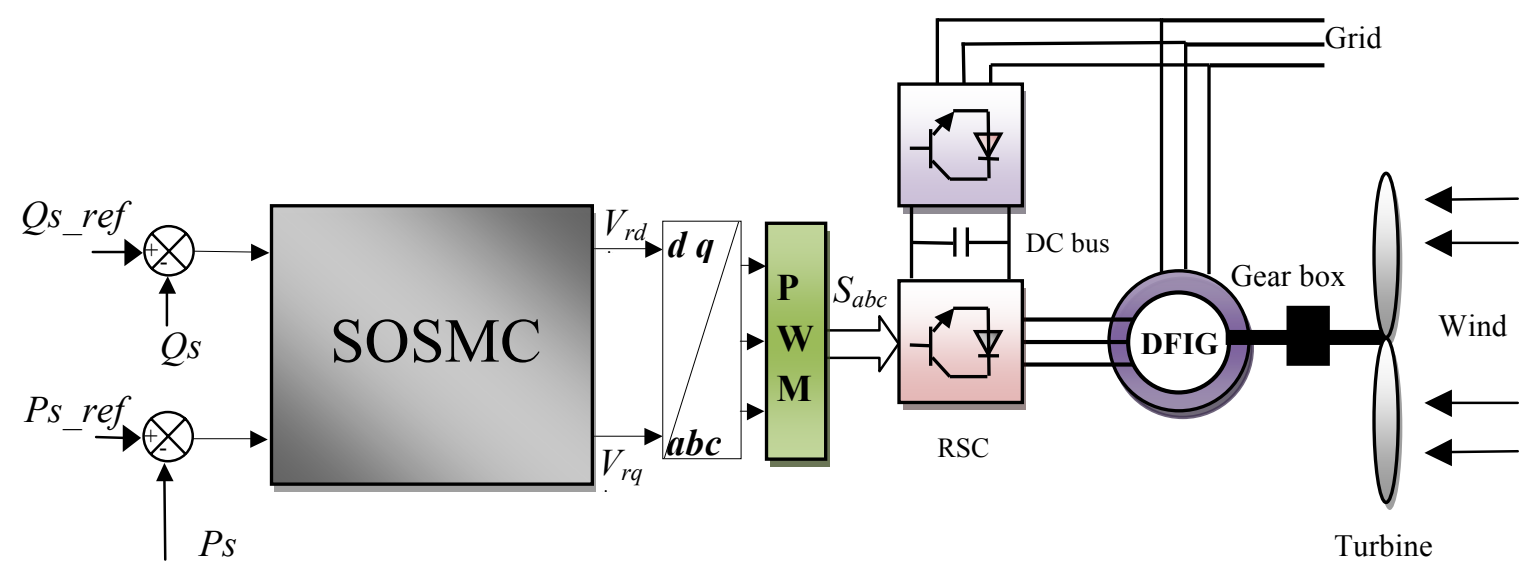

Fig. 5. SOSMC control of a DFIG using PWM technique.

The NSOSMC-FSVM goal is to control the stator reactive power and active power of the doubly fed induction generator. In the NSOSMC, reactive power is controlled by means of the direct axis voltage Vrd, while the stator active power is controlled by means of the quadrature axis voltage Vrq. The proposed NSOSMC-FSVM, which is designed to control active and stator reactive powers of the doubly fed induction generator, is shown in Fig. 11.

Table 3. Parameters of the LM for switching controllers

\begin{tabular}{|l|l|}
\hline Parameters of the LM & Values \\
\hline Number of hidden layer & 08 \\
\hline TrainParam.Lr & 0.005 \\
\hline TrainParam.show & 50 \\
\hline TrainParam.eposh & 2000 \\
\hline $\begin{array}{l}\text { Coeff of acceleration of } \\
\text { convergence (mc) }\end{array}$ & 0.9 \\
\hline TrainParam.goal & 0 \\
\hline TrainParam.mu & 0.9 \\
\hline Functions of activation & Tensing, Purling, gensim \\
\hline
\end{tabular}

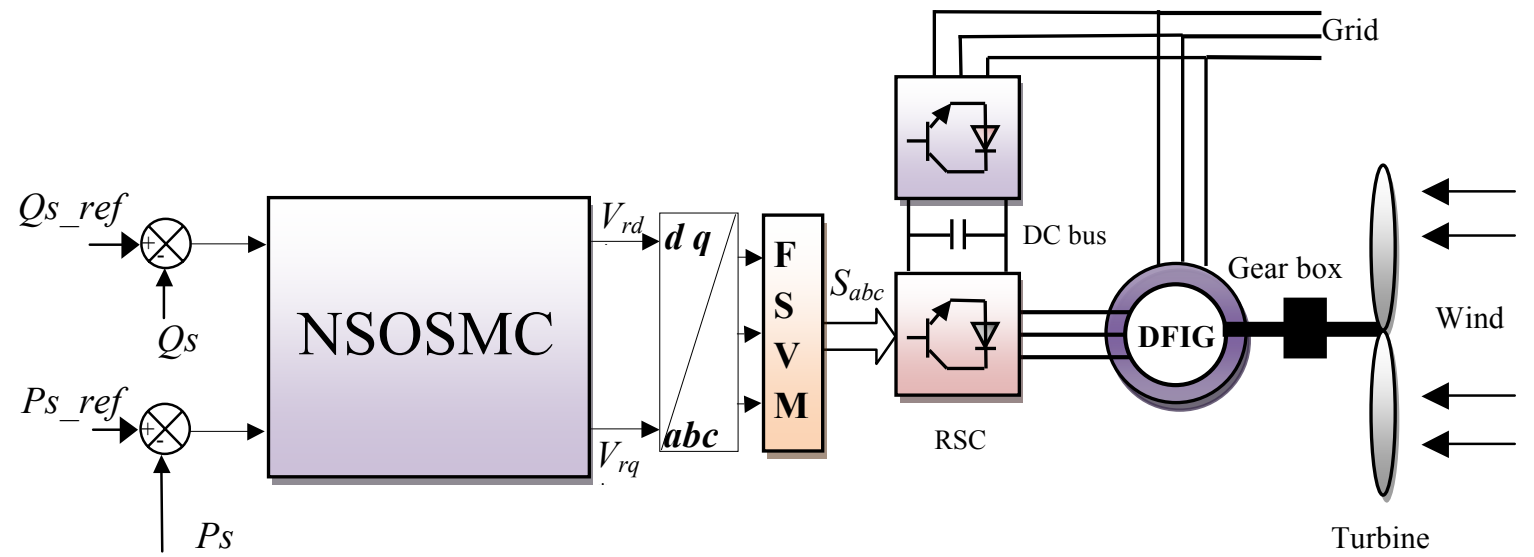

Fig.11. NSOSMC control of the DFIG using FSVM technique. 


\section{Simulation results}

The simulation results of NSOSMC control with FSVM technique of the doubly fed induction generator are compared to conventional SOSMC with PWM. For this end, the controls system was tested under deferent operating conditions such as sudden change of load active and reactive powers, Robustness test and rotor current harmonics distortion. The performance analysis is done with the THD value of rotor current, active stator power, reactive stator power and electromagnetic torque. On the other hand, the parameters of the doubly fed induction generator are given in Table 4 (See Appendix).

\subsection{Reference tracking test (RTT)}

Figs. 12-13 shows the harmonic spectrums of one phase rotor current of the doubly fed induction generator obtained using FFT (Fast Fourier Transform) technique for two-level SOSMC-PWM and two-level NSOSMC-FSVM one respectively. Table 5 shows the comparative analysis of THD value. It can be clear observed that the THD is minimized for two-level NSOSMC-FSVM control (THD $=0.09 \%$ ) when compared to two-level SOSMC-PWM $($ THD $=0.21 \%)$.

Figs. 14-16 show the obtained simulation results. For the proposed command strategies, the active and reactive power tracks almost perfectly their references values. Moreover, the NSOSMC-FSVM control scheme minimized more and more the powers ripples and electromagnetic torque ripple compared to the SOSMC-PWM control technique (See Figs. 17-19).

Table 5. Comparative analysis of THD value (RTT)

\begin{tabular}{|l|c|c|}
\cline { 2 - 3 } \multicolumn{1}{c|}{} & \multicolumn{2}{c|}{ THD (\%) } \\
\cline { 2 - 3 } \multicolumn{1}{c|}{} & SOSMC-PWM & NSOSMC-FSVM \\
\hline Rotor current & 0.21 & 0.09 \\
\hline
\end{tabular}
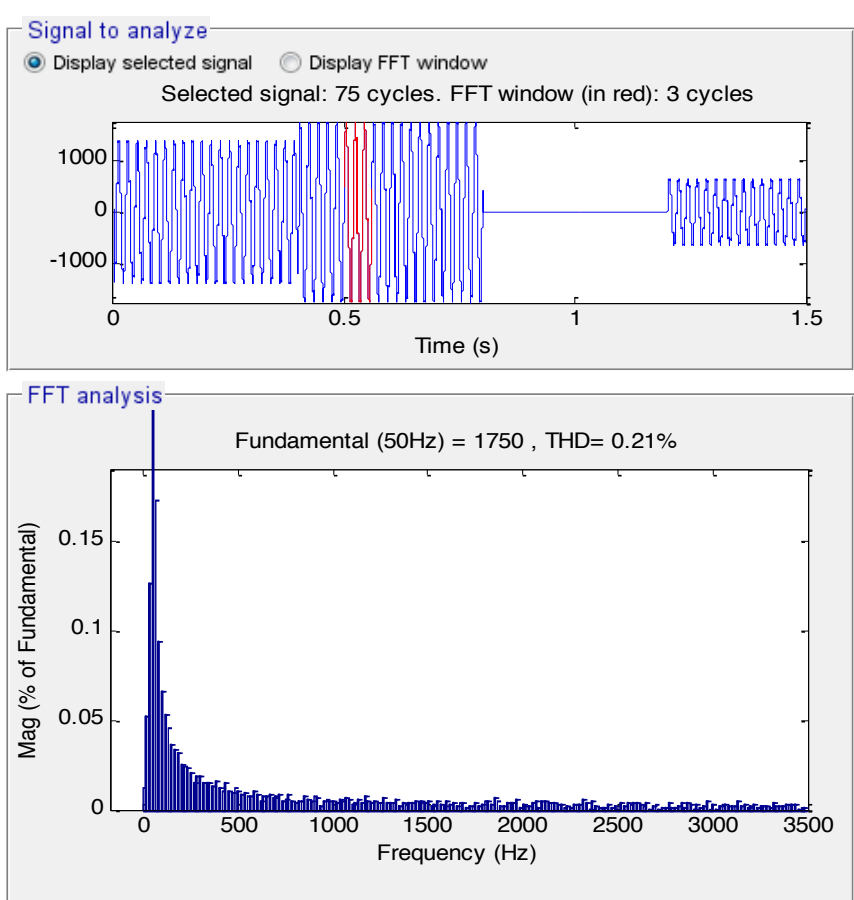

Fig. 12. THD of rotor current for SOSMC-PWM control (RTT).
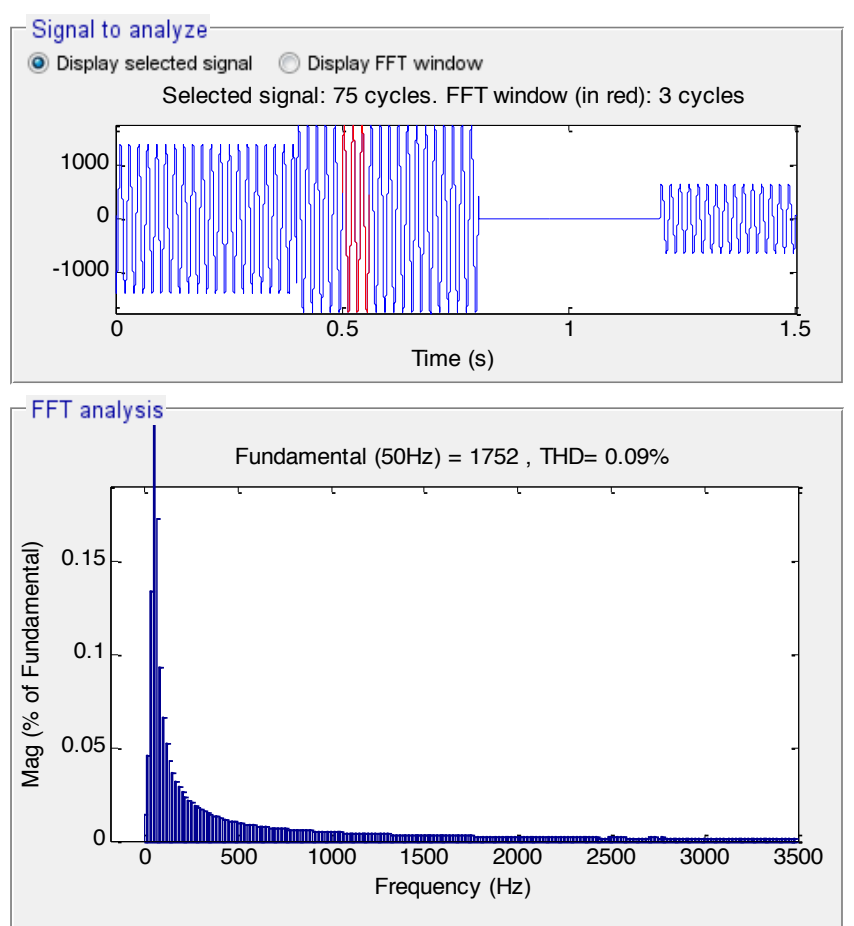

Fig. 13. THD of rotor current for NSOSMC-FSVM control (RTT).

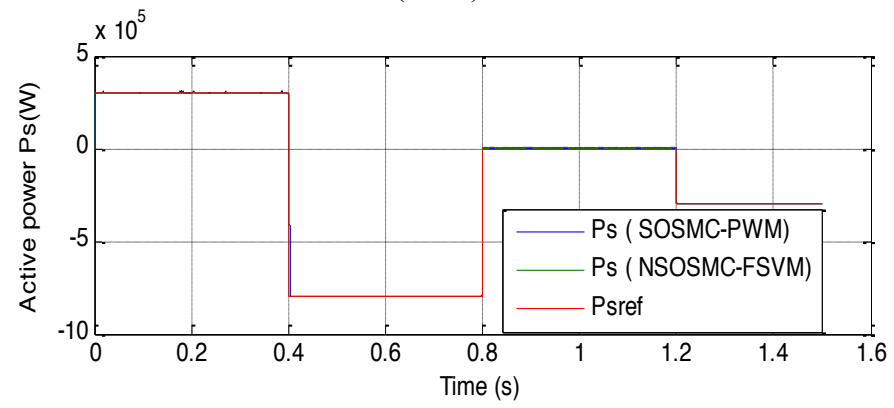

Fig. 14. Active power (RTT).

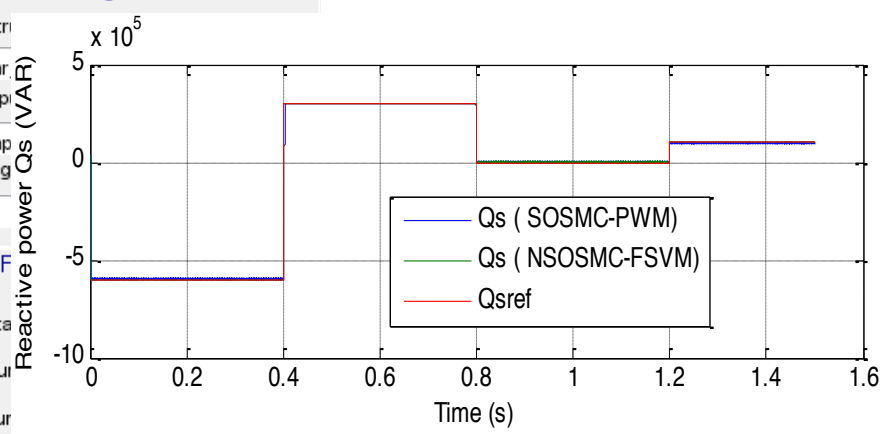

Fig. 15. Reactive power (RTT).

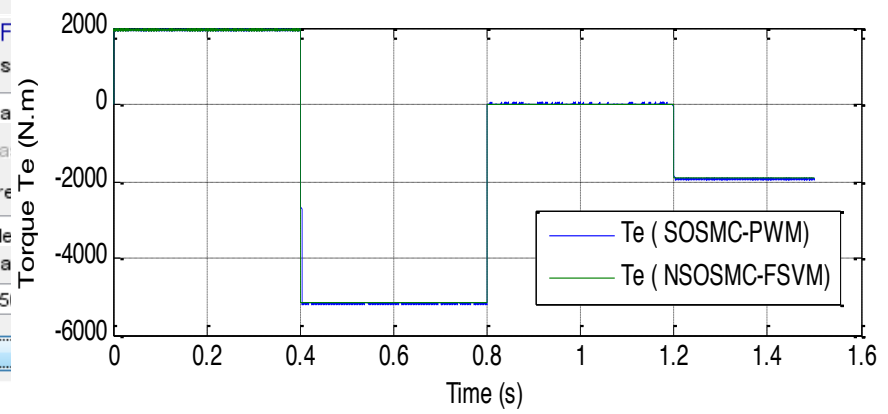

Fig. 16. Torque (RTT). 


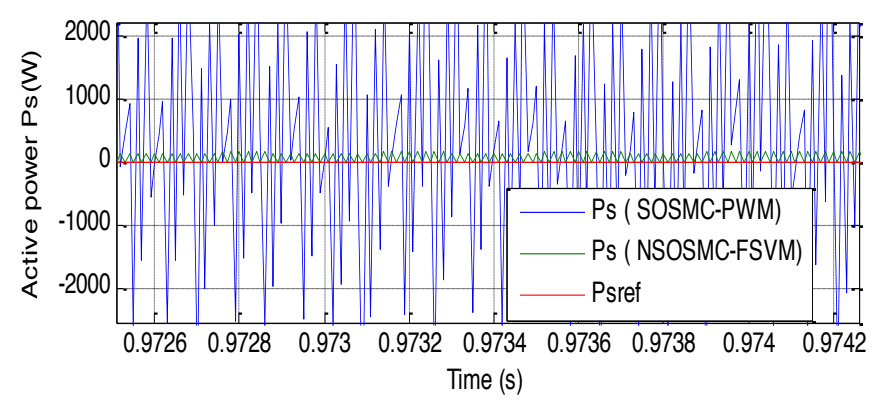

Fig. 17. Zoom in the active power (RTT).

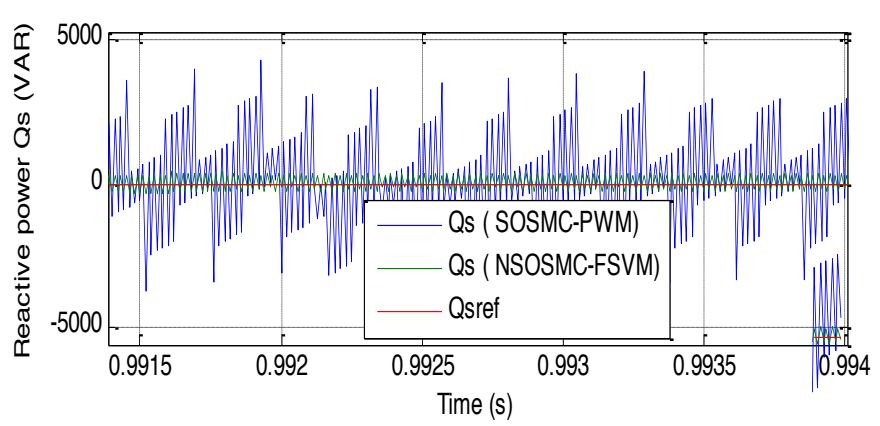

Fig. 18. Zoom in the reactive power (RTT).

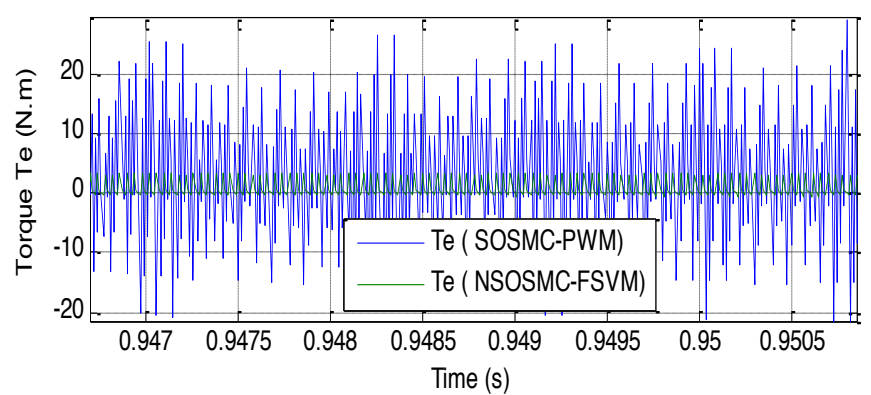

Fig. 19. Zoom in the torque (RTT).

\subsection{Robustness test (RT)}

In this part, the nominal value of the $\mathrm{R}_{\mathrm{r}}$ and $R_{S}$ is multiplied by 2 , the values of inductances $L_{s}, \mathrm{M}$, and $\mathrm{L}_{\mathrm{r}}$ are multiplied by 0.5. Simulation results are presented in Figs. 20-24. As it's shown by these Figures, these variations present a clear effect on the reactive power, active power, and torque curves and that the effect appears more important for the SOSMC-PWM compared to NSOSMC-FSVM (See Figs. 25-27). On the other hand, the THD value of rotor current in the NSOSMC-FSVM control technique has been minimized significantly (See Figs 20-21). Thus it can be concluded that the NSOSMC-FSVM control is more and more robust than the SOSMC-PWM control.
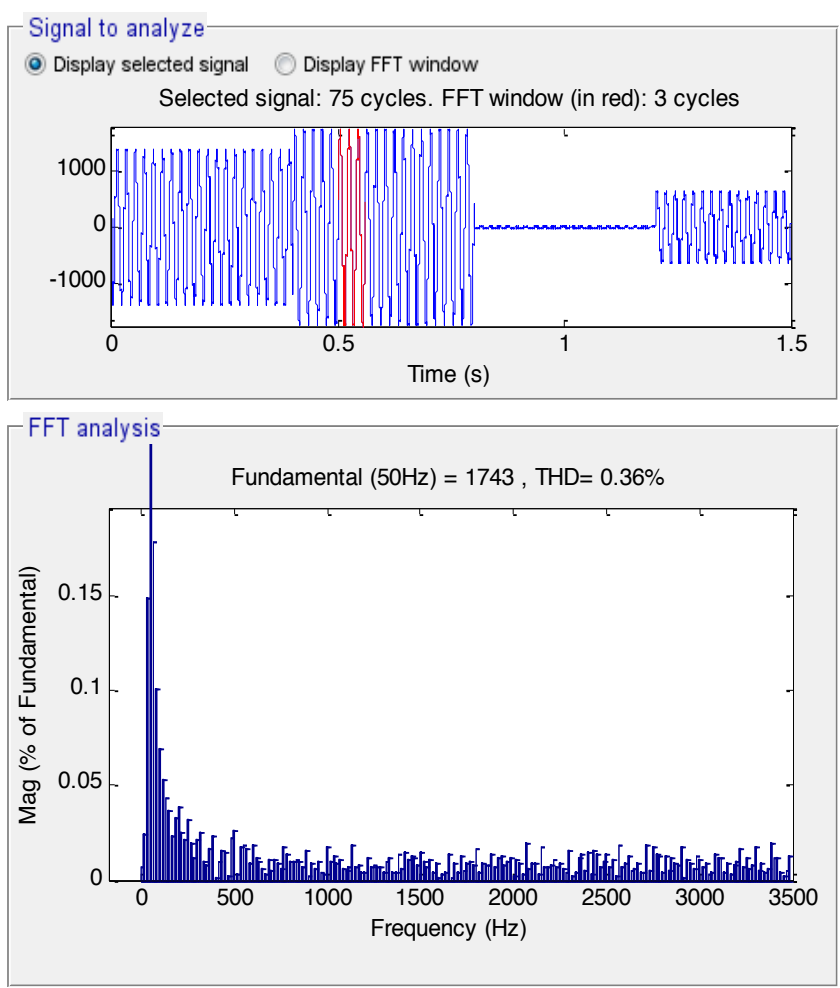

Fig. 20. THD of rotor current for SOSMC-PWM control (RT).
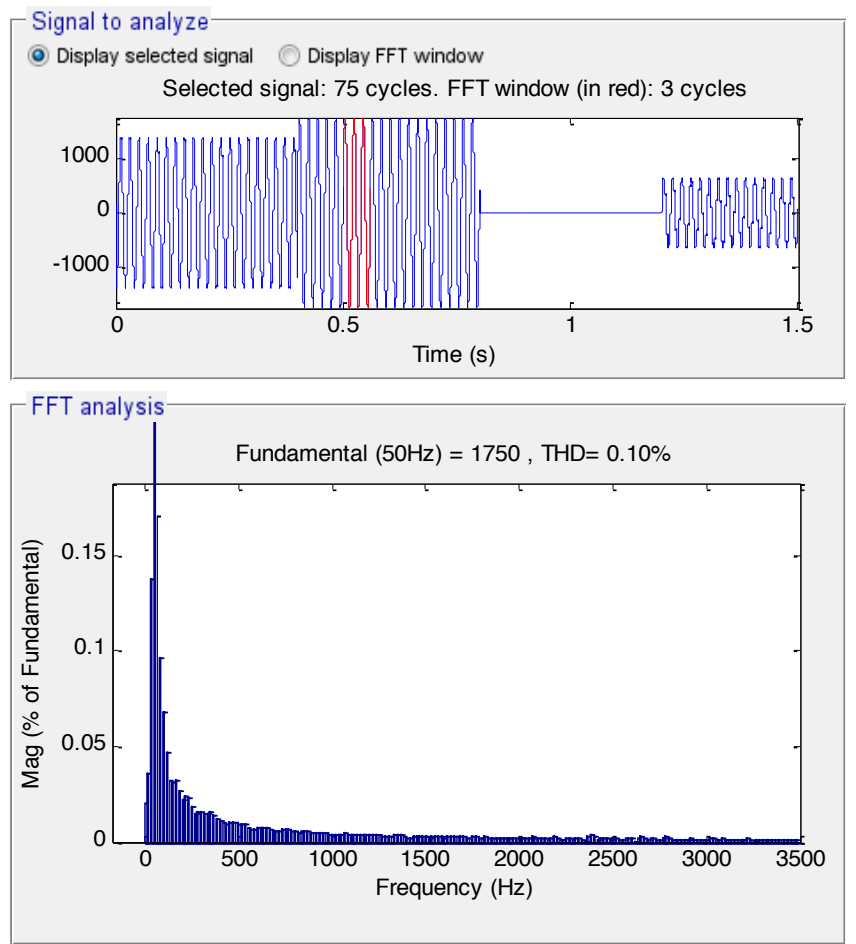

Fig. 21. THD of rotor current for NSOSMC-FSVM control (RT). 


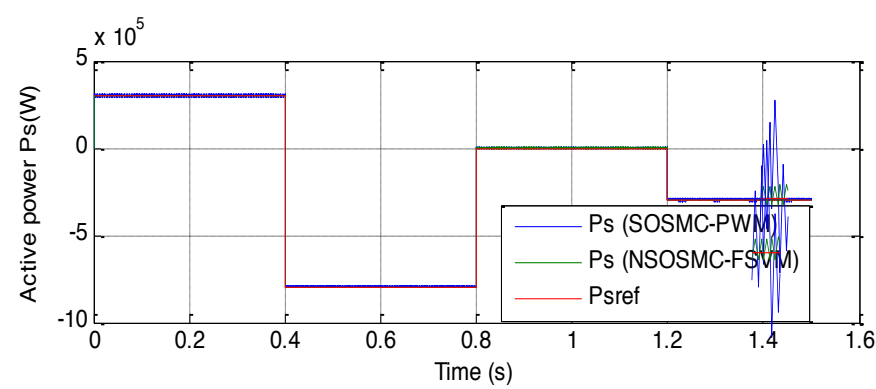

Fig. 22. Active power (RT).

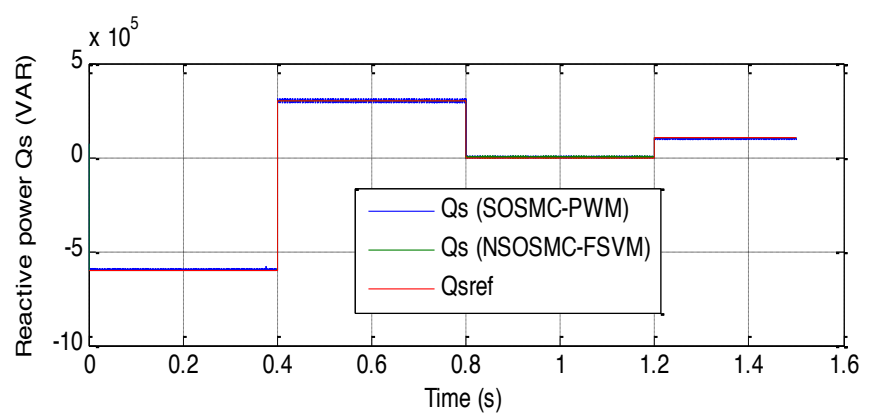

Fig. 23. Reactive power (RT).

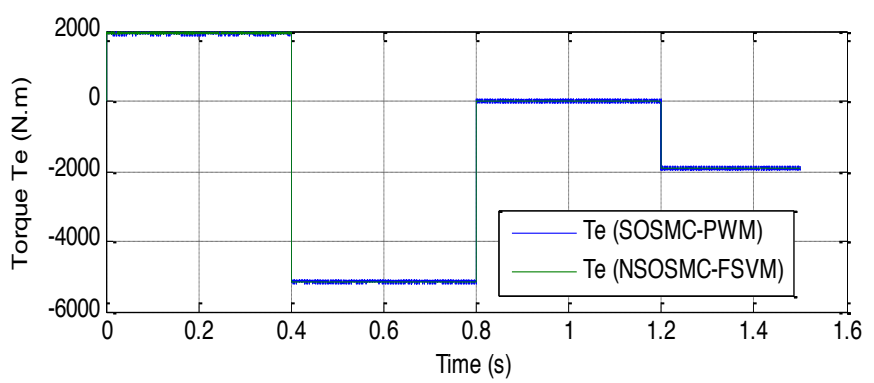

Fig. 24. Torque (RT).

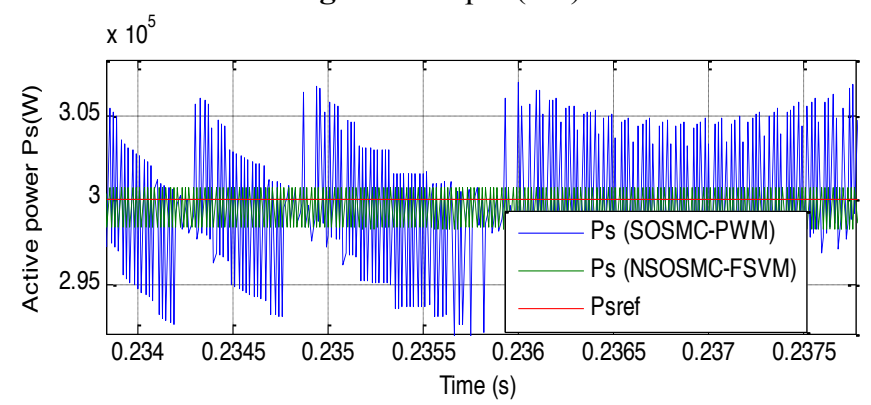

Fig. 25. Zoom in the active power (RT).

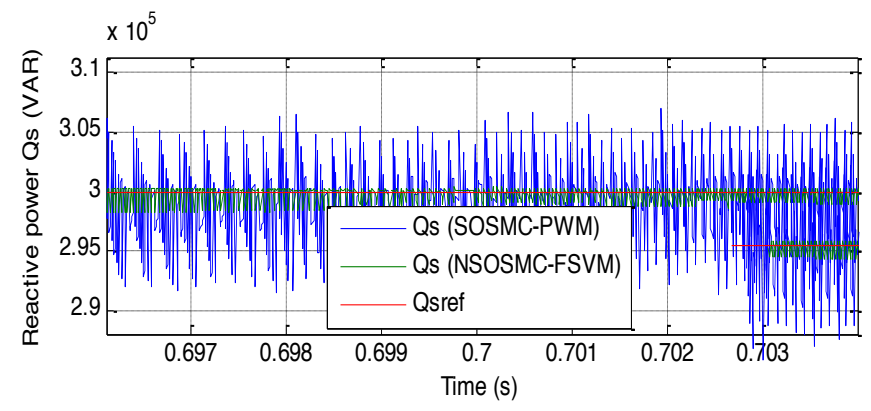

Fig. 26. Zoom in the reactive power (RT).

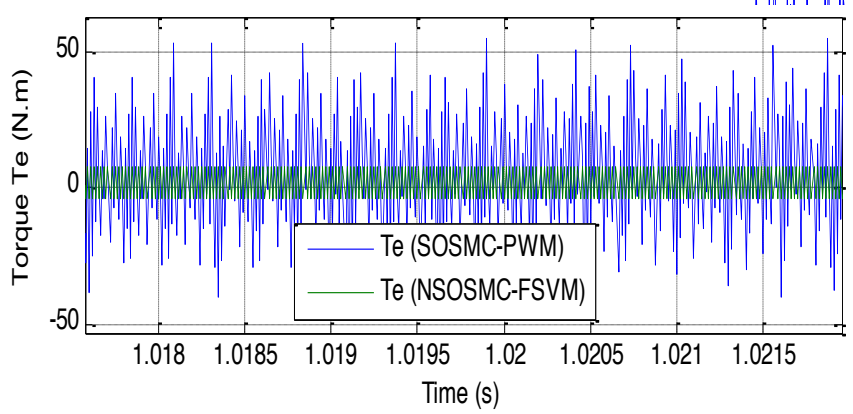

Fig. 27. Zoom in the torque (RT).

\section{Conclusion}

In this article, we proposed a now SOSMC technique based on the artificial neural networks controllers (NSOSMC) to control reactive stator and active stator powers of the doubly fed induction generator by using fuzzy space vector modulation. The simulation results obtained for the NSOSMC control with FSVM strategy illustrate a considerable reduction in electromagnetic torque ripple, active power ripple, reactive power ripple and THD value of rotor current compared to the SOSMC control with traditional PWM technique.

\section{Appendix}

a) Classical SVM technique

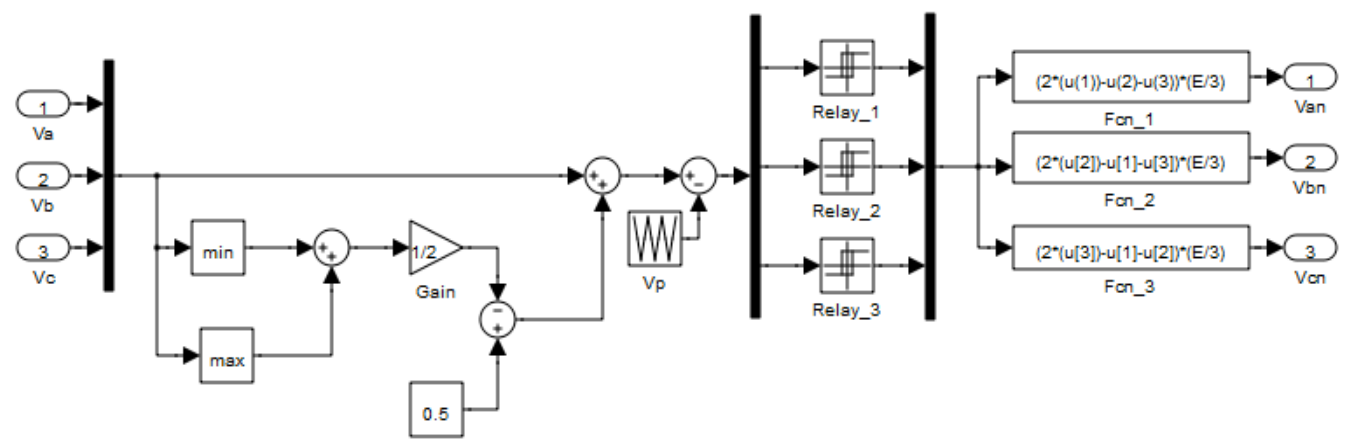

Fig. 1 Block diagram of two-level SVM technique. 


\section{b) FSVM technique}

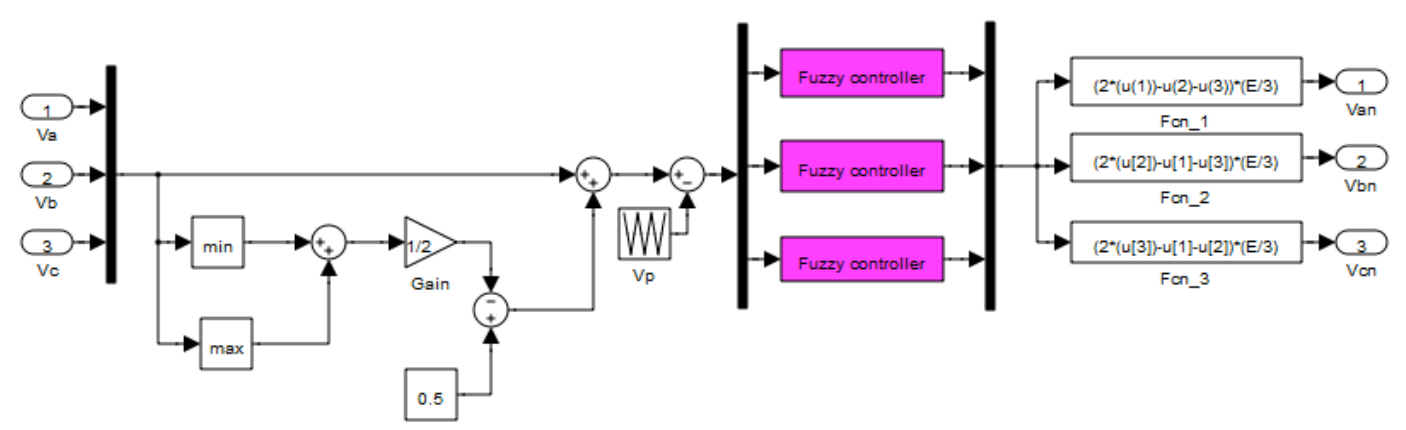

Fig. 2. Block diagram of two-level FSVM technique.
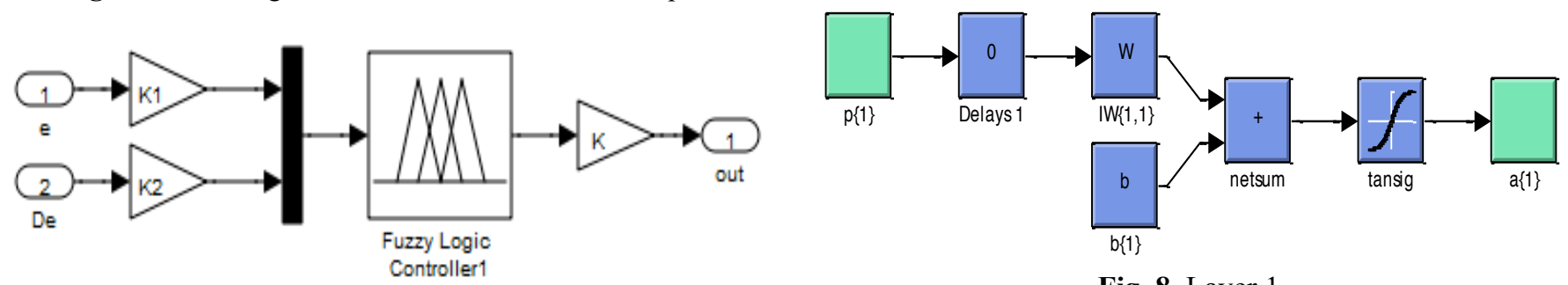

Fig. 8. Layer 1.

Fig. 3. Block diagram of the FL controllers.

c) NSOSMC control
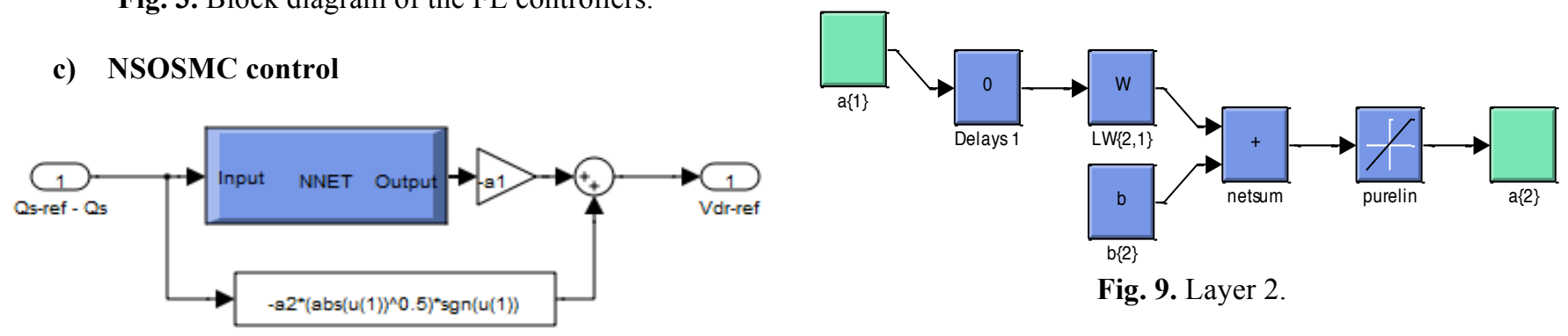

Fig. 9. Layer 2.

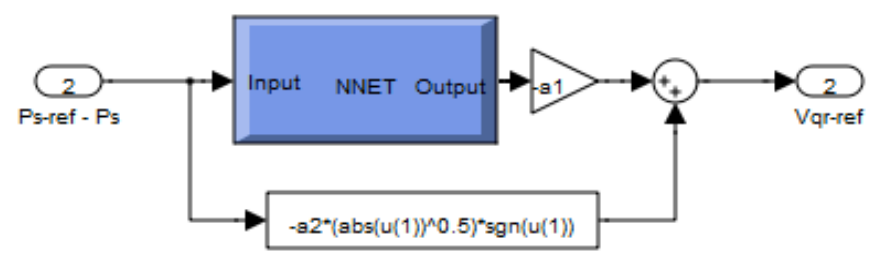

Fig. 6. The block diagram for NSOSMC controller.
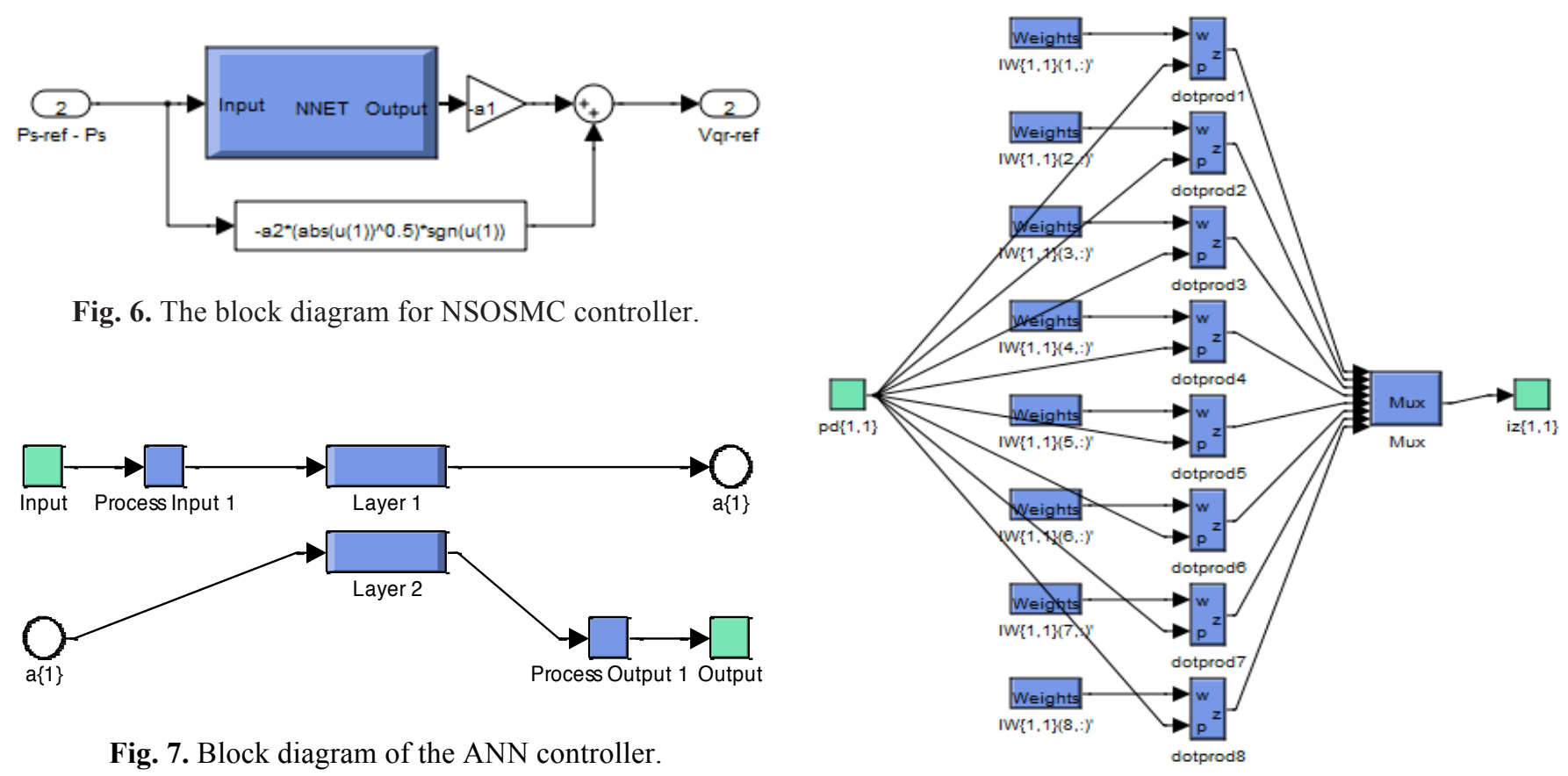

Fig. 7. Block diagram of the ANN controller.

Fig. 10. Block diagram of the hidden layer. 
d) Parameters of the DFIG machine

Table 4. The DFIG Parameters.

\begin{tabular}{|l|l|l|}
\hline Parameters & Rated Value & Unity \\
\hline $\mathrm{P}$ & 1.5 & $\mathrm{MW}$ \\
\hline $\mathrm{Vs}$ & 398 & $\mathrm{~V}$ \\
\hline $\mathrm{Fs}$ & 50 & $\mathrm{~Hz}$ \\
\hline $\mathrm{P}$ & 2 & \\
\hline $\mathrm{Rs}$ & 0.012 & $\Omega$ \\
\hline $\mathrm{Rr}$ & 0.021 & $\Omega$ \\
\hline $\mathrm{Ls}$ & 0.0137 & $\mathrm{H}$ \\
\hline $\mathrm{Lr}$ & 0.0136 & $\mathrm{H}$ \\
\hline $\mathrm{M}$ & 0.0135 & $\mathrm{H}$ \\
\hline $\mathrm{J}$ & 1000 & $\mathrm{Kg} \mathrm{m}$ \\
\hline $\mathrm{f}$ & 0.0024 & $\mathrm{Nm} . \mathrm{s} / \mathrm{rad}$ \\
\hline
\end{tabular}

\section{Reference}

[1] Z. Boudjema, A. Meroufel, Y. Djerriri, E. Bounadja, « Fuzzy sliding mode control of a doubly fed induction generator for wind energy conversion, » Carpathian Journal of Electronic and Computer Engineering, Vol. 6, No. 2, pp. 7-14, 2013.

[2] A. Yahdou, B. Hemici, Z. Boudjema, « Second order sliding mode control of a dual-rotor wind turbine system by employing a matrix converter, » Journal of Electrical Engineering, Vol. 16, No. 3, pp. 1-11, 2016.

[3] S. E. Ardjoun, M. Abid, « Fuzzy sliding mode control applied to a doubly fed induction generator for wind turbines, " Turkish Journal of Electrical Engineering \& Computer Sciences, Vol. 23, pp. 1673-1686, 2015.

[4] Z. Boudjema, R. Taleb, Y. Djerriri, A. Yahdou, «A novel direct torque control using second order continuous sliding mode of a doubly fed induction generator for a wind energy conversion system, » Turkish Journal of Electrical Engineering \& Computer Sciences, Vol. 25, pp. 965-975, 2017.

[5] H. Benbouhenni, Z. Boudjema, A. Belaidi, « Neurosecond order sliding mode control of a DFIG supplied by a two-level NSVM inverter for wind turbine system, » Iranian Journal of Electrical and Electronic Engineering, Vol. 14, No. 4, pp. 362-373, 2018.

[6] D. Kairous, R. Wamkeue, « DFIG-based fuzzy slidingmode control of WECS with a flywheel energy storage, » Electr. Power Syst. Res, Vol. 93, pp. 16-23, 2012.

[7] A. Bouyekni, R. Taleb, Z. Boudjema, H. Kahal, «A second-order continuous sliding mode based on DPC for wind-turbine-driven DFIG, » Elektrotehniški Vestnik, Vol. 85, No.1-2, pp. 29-36, 2018.

[8] A. Kerboua, M. Abid, «Hybrid fuzzy sliding mode control of a doubly-fed induction generator speed in wind turbines,» Journal of Power Technologies, Vol. 95, No. 2, pp. 126-133, 2015.
[9] H. Benbouhenni, Z. Boudjema, A. Belaidi, «DFIGbased WT system using FPWM inverter, » International Journal Of Smart Grid, Vol. 2, No. 3, pp.142-154, 2018.

[10] M. Hasni, Z. Mancer, S. Mekhtoub, S. Bacha, «Parametric identification of the doubly fed induction machine, » Energy Procedia, Vol. 18, pp. 177-186, 2012.

[11] N. Mekkaoui, M. Naït-Saïd, « Direct s-power control for a doubly fed induction generator, »Rev. Roum. Sci. Techn.-Electrotechn. Et Energ, Vol. 62, No. 4, pp. 365-370, 2017.

[12] A. Boumediène, L. Abdellah, "A novel sliding mode fuzzy control based on SVM for electric vehicles propulsion system, » ECTI Transactions on Electrical Eng., Electronics and Communications, Vol. 10, No. 2, pp. 153-163, 2012.

[13] S. Allirani, V. B. T. Raaj, « Development of space vector pulse width modulation algorithm for voltage source inverter using dsPIC controller 30F4011, 》 International Journal of Pure and Applied Mathematics, Vol. 114, No. 9, pp. 257-269, 2017.

[14]A. Saritha, T. Abhiran, DR. K. Sumanth, «Space vector pulse width modulation for two level inverter, »" International Journal of Professional Engineering Studies, Vol. 6, No. 3, pp. 8-14, 2016.

[15]H. Benbouhenni, Z. Boudjema, A. Belaidi, « Using three-level Fuzzy space vector modulation method to improve indirect vector control strategy of a DFIG based wind energy conversion systems, » International Journal Of Smart Grid, Vol. 2, No. 3, pp.155-171, 2018.

[16]H. Benbouhenni, Z. Boudjema, A. Belaidi, « Direct vector control of a DFIG supplied by an intelligent SVM inverter for wind turbine system, " Iranian Journal of Electrical and Electronic Engineering, In Press, 2018.

[17] M. H. Reddy, T. B. Reddy, B. R. Reddy, M. S. Kalavathi, "Generalized PWM technique for dual inverter fed induction motor drive, »" Acta Electrotechnica et Informatica, Vol. 14, No. 1, pp. 2836, 2014.

[18] Y. Guo, H. Long, « Self organizing fuzzy sliding mode controller for the position control of a permanent magnet synchronous motor drive, » Ain Shams Engineering Journal, Vol. 2, pp. 109-118, 2011.

[19]H. Khouidmi, A. Benzouaoui, B. Bessedik, « SlidingMode MRAS Speed Estimator for Sensorless Vector Control of Double Stator Induction Motor, » Majlesi Journal of Electrical Engineering, Vol. 12, No. 3, pp. 41-53, 2018.

[20] D. Boudana, L. Nezli, A. Telmcani, M. O. Mahmoudi, M. Tadjine, «Robust DTC based on adaptive fuzzy control of double star synchronous machine drive with fixed switching frequency, » Journal of Electrical Engineering, Vol. 63, No. 3, pp. 133-143, 2012.

[21]A. Abbou, H. Mahmoudi, «Performance of a sensorless speed control for induction motor using DTFC strategy and intelligent techniques, » Journal of Electrical Systems, Vol. 3-5, No. 6, pp. 64-81, 2009. 